\title{
Las máscaras de la alteridad en escuelas platenses
}

\author{
María Verónica Solari Paz \\ Stella Maris García \\ Mariel Betina Cappannini \\ (Universidad Nacional de La Plata. \\ LIAS. Argentina)
}

\section{Resumen}

En este artículo presentamos el complejo escenario de escuelas urbanas que deben responder a los derechos de escolarización de niños y jóvenes indígenas migrantes o hijos de migrantes nacionales o extranjeros. El proceso de radicación de estos grupos domésticos en el oeste del Partido de La Plata, ciudad capital de la provincia de Buenos Aires (Argentina) ha impuesto un perfil singular a los establecimientos educativos públicos de la región. La diversidad en las aulas queda disimulada por dos vías: cuando los niños/as asumen el rol de 'alumnos' ya connotado con determinadas formas de comportamientos esperados y cuando se construyen estrategias discursivas que enmascaran las relaciones y las prácticas en la escuela. Los reclamos por una educación intercultural efectiva aun no logran derribar las máscaras racistas, romper los estereotipos ni educar para una existencia cultural alterna. La etnografía escolar nos ha permitido señalar que no se trata de voluntarismo ni de leyes bien formuladas sino de construir profundas transformaciones a nivel de las relaciones sociales.

\section{Palabras clave}

Indígenas en la Ciudad - Etnografía Escolar - Diversidad en el Aula - Estereotipos.

\section{Summary}

In this article we presented the complex scene of urban schools that must respond to the rights of education of children and teenagers from national or international backgrounds. The process of radication of these domestic groups in the west of $\mathrm{La}$ Plata, capital of the province of Buenos Aires Argentina, has imposed a singular profile to the regional educational public establishments. The diversity in the classrooms is disguised by two ways: when children assume the role of 'students' already connoted with determined forms of awaited behaviours and when constructed discursive strategies mask the relations and the practices in the school. The claim of an effective intercultural 
education has not yet manage to demolish the racist masks, to break the stereotypes nor to educate for an alternating cultural existence. The scholastic ethnography has allowed us to indicate that it isn't voluntarism or well formulated laws, but to construct a deep transformation to level of the social relations.

\section{Key words:}

Natives in the City - Scholastic Ethnography - Diversity in the Classroom Stereotypes.

\section{La alteridad oculta}

La presencia de "otros" niños/niñas se ha tornado cotidiana en las escuelas de la región oeste del Partido de La Plata, ciudad capital de la provincia de Buenos Aires (Argentina), donde llevamos adelante nuestro proyecto de investigación antropológica. En este artículo, a partir del registro etnográfico en las instituciones educativas, sus contextos barriales y de los testimonios relevados en situaciones escolares, nos proponemos reflexionar acerca de las 'máscaras' que ocultan la alteridad en la escuela. La variable étnica fue apareciendo en nuestras notas de campo indicando la presencia de niños Qom (Tobas), Aymaras, Quechuas, Kollas, Gitanos, hablantes de guaraní, entre otros, a pesar de que en los registros de inscripción de las escuelas solamente se anota la nacionalidad. Vemos aquí que la categoría de nacionalidad encubre otras identidades étnicas subsumidas por procesos sociohistóricos de conquista, colonización y de constitución de los estados-nación. Esta categoría también opera a nivel de las relaciones sociales como prejuicio, discriminación, exclusión, negación, tal es el caso de los calificativos de "bolita", "paragua", "peruca" que se escuchan en los recreos, en las disputas entre pares, haciendo alusión a las nacionalidades Boliviana, Paraguaya, etc. Esta situación complejiza aún más los mecanismos de articulación de la escuela con el espacio barrial donde reside el niño o el joven.

Si bien los procesos migratorios fueron el motor del poblamiento del vasto territorio argentino, éstos respondieron a causalidades diferentes según los contextos histórico-económicos que atravesó el país (1). En esta región, la destrucción de las economías regionales, resultado del proceso de concentración del capital en los últimos veinte años (2), desencadenó movimientos migratorios que incluyeron a centenares de familias "expulsadas" de sus lugares de origen. De este modo, migrantes internos y de países limítrofes se aglutinaron en los alrededores de los centros urbanos 
que -en nuestro referente empírico- le otorgaron perfiles singulares a las escuelas, definiendo nuevos desafíos en torno a los procesos de enseñanzaaprendizaje, al tener que conjugar no sólo las clásicas variables referidas al género, edad, clase social sino a lo étnico, la nacionalidad, la religión, entre otras.

La presencia de indígenas en las ciudades, en tanto nacidos y criados en territorio de la Nación Argentina, se ha dado desde los inicios mismos de la organización urbana. Pero cabe subrayar que esa presencia ha tenido en las relaciones sociales un denominador común a lo largo de nuestra historia: la forma de doble negación, tanto por el mismo indio como por el no indio. Los procesos de conquista y colonización organizaron socialmente el lugar de las poblaciones originarias minimizando y hasta negando su existencia cultural alterna, bajo las categorías de "salvajes", "bárbaros", "infieles", "paisanos", "campesinos", "peones", "arrieros", "cabecita negra", etcétera.

A fines del siglo XIX, ante la conminación a organizar el Estado Argentino, se institucionaliza con la escuela el disciplinamiento de toda la población desde la más tierna infancia, de forma obligatoria y en términos de "igualdad", una igualdad ficticia, "civilizatoria" y centrada en valores de modernidad. Como expresión de esos valores y del progreso pregonado en esa época se funda, planificada meticulosamente, la ciudad de La Plata; hoy habitada por población étnicamente diversa y con profundas desigualdades sociales.

En ese proceso, la alteridad construida por el Estado Argentino se caracteriza por neutralizar las diferencias dejándolas subsumidas bajo la categoría "ser argentino".

Acordamos con la antropóloga Rita Segato cuando afirma que:

“(...) todas las personas étnicamente marcadas, sea por la pertenencia a una etnia derrotada (los indios y los africanos) o a un pueblo inmigrante (italianos, judíos, españoles, polacos, rusos, sirios y libaneses, alemanes, ingleses y tantos más) fueran convocadas o presionadas para desplazarse de sus categorías de origen para solamente entonces, poder ejercer confortablemente la ciudadanía plena. (...) La nación fue concebida y formulada como una gran etnia artificial, inventada en el laboratorio de la generación de 1880 y reproducida en la escuela mediante una depurada técnica de clonaje" (Segato1997).

Los pueblos originarios a pesar de ser negados, continuaron la lucha por su existencia sin gozar de la atención del estado en cuanto a políticas específicas ni existencia legal como pueblos. Cumplidos los Quinientos Años 
de la Conquista de América logran, en este extremo sur del continente, la formulación formal de sus derechos. A nivel nacional se da con la sanción de la Ley Nacional $\mathrm{N}^{\circ} 23.302$ de Política Indígena y Apoyo a las Comunidades Aborígenes (1985) y su Decreto Reglamentario (1989); la Ley Nacional N ${ }^{\circ}$ 14.932/59 (en relación al Convenio 107 de la Organización Internacional del Trabajo-Organización de las Naciones Unidas); y la incorporación del Artículo 75 Inciso 17 en la Constitución Nacional (3). A nivel provincial se da en las constituciones de: Formosa, Chaco, Salta, Misiones, Río Negro y Neuquén (Ibáñez Caselli et all, 2004).

Los reclamos de los pueblos indígenas sobre el derecho a la tierra, a una existencia cultural alterna, están posibilitando repensar y reconocer su presencia en las ciudades (Tamagno, 2001), sistematizar mecanismos de ayudas para que niños y jóvenes finalicen los diferentes niveles de instrucción educativa y promover desde las políticas oficiales una "educación intercultural bilingüe" (4). Esta modalidad comenzó siendo pensada en las provincias del interior para escuelas rurales o peri-urbanas con población mayoritariamente indígena, tal como así lo demuestran los programas de becas para estudiantes indígenas, sin embargo esto aún no ha sido resuelto en escuelas de ámbitos urbanos.

\section{Máscaras en el espacio social}

Tomamos el espacio como una variable a investigar dado que en él acontecen los procesos socioculturales a lo largo del tiempo; el espacio refiere además a convergencias o divergencias de discursos y categorías mentales que atribuyen ciertas cualidades a las condiciones objetivas del mundo físico. Estas representaciones pueden convertirse en la matriz de las inferencias sobre los demás aspectos de la realidad, y a su vez significar el patrón de acción y las medidas de las categorizaciones a seguir en la vida cotidiana. Por ejemplo, del docente al alumno, de la escuela hacia el barrio, del vecino hacia los recién llegados (indígenas, migrantes de países limítrofes, pobres, entre otros), etcétera.

Estas construcciones remiten a imaginarios sociales que definen diferentes posturas explicativas acerca de las percepciones del mundo en que se vive y operan en la situación educativa. En este sentido algunos testimonios revelan estas clasificaciones:

“... ésta es una población muy carenciada".

"Aquí asisten 480 alumnos a nivel primario. Le damos merienda reforzada. Hay chicos que tienen dificultades en el aprendizaje por las carencias que tienen, no vienen bien alimentados al pertenecer a familias destruidas, algunos viven con la abuela, otros 
viven con el papá, otros viven con la mamá, .... hay hermanos pero que tienen diferentes apellidos". "... las madres vienen a la escuela vestidas de gitanas. Y si vos ves, yo tengo señoras bolivianas que vienen con los chicos colgando por la espalda. Es su cultura, nosotros los respetamos. Pero es lo tradicional para ellos. Se sientan en el piso, por ejemplo, les das las sillas pero ellas no las quieren. Hay muchas peculiaridades...".

"... Son quinteros algunos, hay mucha población boliviana, otros dependen del Plan Trabajar o del Plan Jefes y Jefas de Hogar; muy pocos tienen realmente un trabajo estable, es la característica de toda la zona" (5).

Contrastamos este panorama con nuestra investigación de campo para afirmar que el empleo de consideraciones simplistas estereotipadas enmascara realidades y fomenta justificativos que terminan victimizando a niños, jóvenes y a sus familias.

Tomamos como punto de partida los análisis socio-antropológicos de construcción de la realidad (Berger y Luckmann, 1976) y su empleo en el análisis de lo escolar (Maimone y Edelstein, 2004). El proceso de institucionalización del espacio escolar está siempre moldeado por las circunstancias históricas de la propia institución y de la sociedad en la que está inmersa, en una dinámica compleja que conjuga necesidades, intereses, planes de acción que se fueron sedimentando y reformulando, mecanismos legitimadores, definición de roles, universos simbólicos que le otorgan valores.

Cabe señalar aquí que la escuela argentina se formalizó como tal legitimada por un discurso político-pedagógico, de larga vigencia en el país, que la define como templo de lo culto, de la civilización, de la salud, de la patria, de la tradición, de la razón, de la ciencia, de lo público que irradia estos bienes sobre el exterior, reino de lo inculto, de la barbarie, de la enfermedad, de la antipatria, de la novedad, de la irracionalidad, del azar, del saber no científico, de la ley de la selva (Pineau, 2005). Esta concepción de la lógica escolar regula espacios que serían extraños entre sí: el adentro y el afuera escolar.

Nuestra hipótesis sostiene que dicha lógica persiste en el imaginario de amplios sectores de la población, se expresa en los rituales escolares y se enmascara en los discursos y prácticas cotidianas haciendo 'como si' se educara en la igualdad.

Recurrimos al concepto de articulación social propuesto por el antropólogo argentino Leopoldo Bartolomé (1975) para describir cómo la escuela se estructura en relación al barrio, las características peculiares de ese contexto exterior, ese afuera escolar desde las actividades y su funcionamiento general. Y paralelamente damos cuenta de cómo esas 
circunstancias aparecen en el adentro escolar en una relación dialéctica de articulación (6).

Una zona del partido de La Plata que se pobló en los últimos veinticinco años, con migrantes de países limítrofes y de diferentes localidades del interior del país es la que identificamos como referente empírico.

Conjugamos información cualitativa y el análisis de los censos de población con los índices de Necesidades Básicas Insatisfechas (7) que informa la Dirección de Estadística Provincial para definir los sectores caracterizados por poblamiento reciente y alto índice de NBI. Para el municipio de La Plata en el año 2001 este porcentaje era del 10\%, lo cual implica unos 18.211 hogares.

Tabla 1. Partido de La Plata. Hogares con NBI según centro comunal. Año 2001.

\begin{tabular}{|l|r|r|r|r|r|}
\hline $\begin{array}{c}\text { La Plata - centros } \\
\text { comunales }\end{array}$ & \multicolumn{2}{|c|}{$\begin{array}{c}\text { Hogares } \\
\text { con NBI }\end{array}$} & \multicolumn{2}{c|}{$\begin{array}{c}\text { Total de } \\
\text { hogares }\end{array}$} & $\begin{array}{c}\text { \% NBI s/total } \\
\text { hogares }\end{array}$ \\
\hline Casco & 1855 & $10,19 \%$ & 70136 & $39,63 \%$ & $2,64 \%$ \\
\hline Villa Elvira & 2408 & $13,22 \%$ & 16037 & $9,06 \%$ & $15,02 \%$ \\
\hline Los Hornos & 2384 & $13,09 \%$ & 15215 & $8,60 \%$ & $15,67 \%$ \\
\hline San Carlos & 1800 & $9,89 \%$ & 11797 & $6,67 \%$ & $15,26 \%$ \\
\hline Tolosa & 1289 & $7,08 \%$ & 12743 & $7,20 \%$ & $10,12 \%$ \\
\hline City Bell & 917 & $5,04 \%$ & 9246 & $5,22 \%$ & $9,92 \%$ \\
\hline San Lorenzo & 1626 & $8,93 \%$ & 8525 & $4,82 \%$ & $19,07 \%$ \\
\hline Gonnet & 442 & $2,43 \%$ & 6963 & $3,93 \%$ & $6,35 \%$ \\
\hline Melchor Romero & 1755 & $9,64 \%$ & 4855 & $2,74 \%$ & $36,15 \%$ \\
\hline Villa Elisa & 543 & $2,98 \%$ & 5726 & $3,24 \%$ & $9,48 \%$ \\
\hline Olmos & 738 & $4,05 \%$ & 3409 & $1,93 \%$ & $21,65 \%$ \\
\hline Ringuelet & 424 & $2,33 \%$ & 3928 & $2,22 \%$ & $10,79 \%$ \\
\hline Abasto & 716 & $3,93 \%$ & 2739 & $1,55 \%$ & $26,14 \%$ \\
\hline Hernández & 360 & $1,98 \%$ & 1969 & $1,11 \%$ & $18,28 \%$ \\
\hline Seguí & 407 & $2,24 \%$ & 1500 & $0,85 \%$ & $27,13 \%$ \\
\hline Gorina & 205 & $1,13 \%$ & 936 & $0,53 \%$ & $21,90 \%$ \\
\hline Etcheverry & 172 & $0,94 \%$ & 717 & $0,41 \%$ & $23,99 \%$ \\
\hline El Peligro & 16209 & $0,92 \%$ & 536 & $0,30 \%$ & $31,34 \%$ \\
\hline Total & $100,00 \%$ & 176977 & $100,00 \%$ & $10,29 \%$ \\
\hline & & & & & \\
\hline
\end{tabular}

Fuente: Elaborado en base al Censo Nacional de Población, Hogares y Viviendas 2001. 
Al examinar lo acontecido con dicho indicador, pueden distinguirse tres grandes grupos. Aquellos que presentan mayor proporción de hogares con NBI (Melchor Romero, Lisandro Olmos, Abasto, Arturo Seguí, Gorina, Etcheverry y El Peligro). Aquí residen familias quechuas, aymaras y kollas. En un segundo grupo se ubican los centros que poseen entre $11 \%$ y $19 \%$ de sus hogares con NBI (Villa Elvira, Los Hornos, San Carlos, San Lorenzo, Ringuelet y Hernández), incluye los nucleamientos qom (tobas).

Por último, restan los que poseen a lo sumo el $10 \%$ de sus hogares con NBI (Casco, Tolosa, City Bell, Gonnet, Villa Elisa).

Gráfico 1. Comparación de los hogares con NBI sobre el total de hogares de los centros comunales del Partido de La Plata.

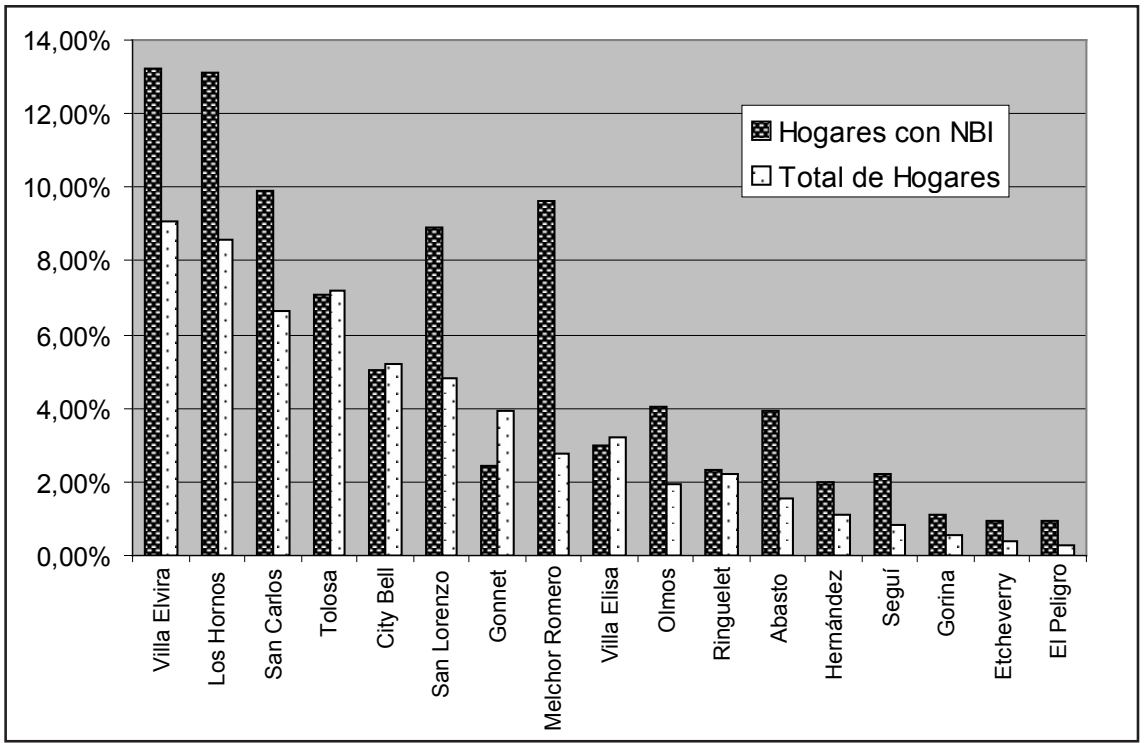

Fuente: Elaboración propia a partir de Tabla 1.

Este gráfico arroja diferencias entre hogares y hogares con necesidades básicas insatisfechas, elemento que tomamos en cuenta para definir los sectores a explorar.

Podemos apreciar en el mismo, la disminución de hogares con necesidades básicas insatisfechas a medida que nos acercamos al casco y a los centros comunales del norte. Localizamos las escuelas objeto de estudio en la zona sur a fin de atender la diversidad y desigualdad, y cómo ésta se manifiesta. Prospectamos el entorno a partir de recorridas, observaciones 
y registros de testimonios, que cotejamos con análisis cartográfico, actual e histórico. Esto nos permitió ampliar y precisar nuestra visión respecto a la población que asiste a las escuelas de estos sectores, y comenzar a desdibujar las designaciones estereotipadas de "escuela de la pobreza", "escuela estigmatizada", dado que en ellas visualizamos que repercuten las condiciones urbanas de desindustrialización, de precarización laboral y desocupación.

En el área estudiada registramos la desaparición de los hornos de ladriIlo, de fábricas de productos lácteos y vacunos, la presencia de estructuras abandonadas de antiguos talleres, carpinterías, carbonerías, hilanderías, etcétera; pero la permanencia de algunas fábricas, imprentas, depósitos, concesionarios de autos; paralelamente, detectamos que la pérdida de suelos fértiles, ha llevado al reemplazo de la quinta de verduras y hortalizas para el consumo y venta, por el cultivo en invernáculos, empleo de nuevas tecnologías, y contrataciones precarias de trabajadores.

Mapa del Partido de La Plata. Provincia de Buenos Aires. Argentina. Cordón poblacional migrante. Vías de comunicación

y escuelas afectadas al proyecto.

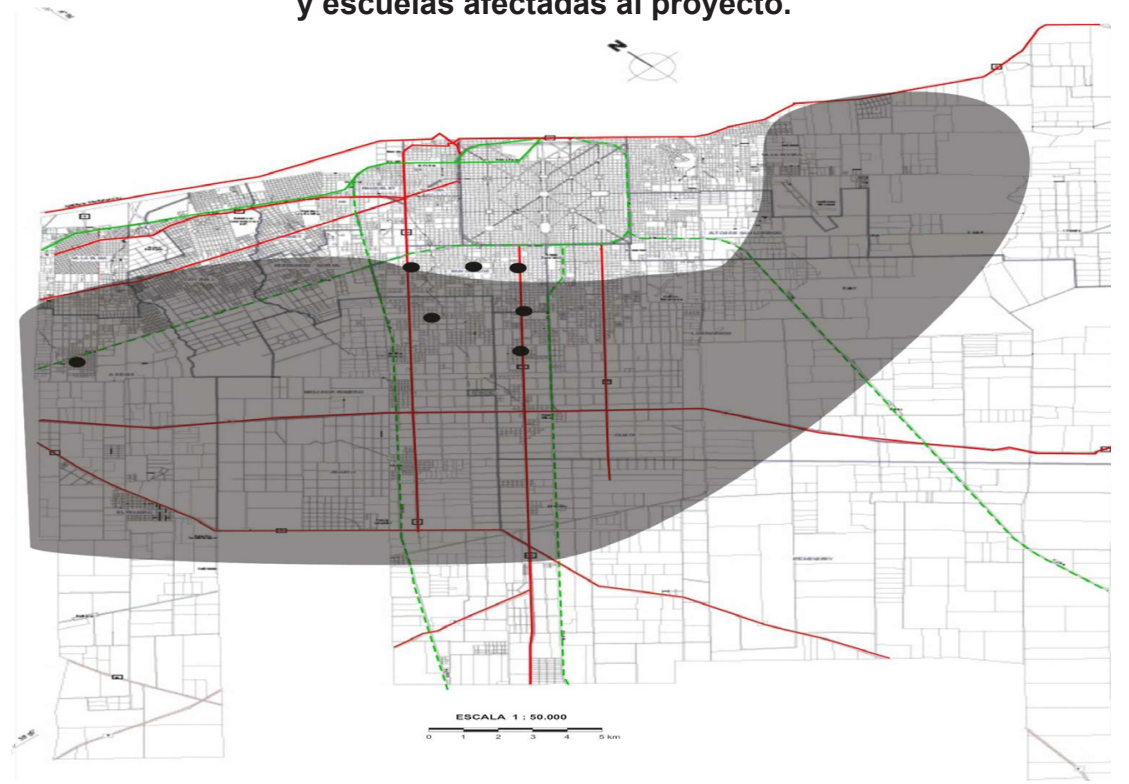

Fuente: Elaboración propia a partir del mapa de Infraestructura de comunicaciones en Hurtado, M. A.: Análisis ambiental del partido de La Plata: Aportes al ordenamiento territorial. Instituto de Geomorfología y Suelos, y Centro de Investigaciones de Suelos y Aguas de Uso Agropecuario (CISAUA). La Plata, 2006. 
Tal como mostramos en el mapa de usos de suelos, identificamos un cordón florihortícola asociado a los cambios socio-económicos-demográficos, configurando un cordón poblacional relacionado en su mayoría con las tareas de producción de flores y hortalizas, constituyéndose este sector como el mayor núcleo productor de la provincia de Buenos Aires, y con la mayor cantidad de explotaciones dedicadas a estos cultivos (Censo Florihortícola, 2005).

Tabla 2. Población según lugar de nacimiento discriminada por centro comunal del Partido de La Plata. Año 2001.

\begin{tabular}{|l|r|r|r|r|r|r|r|}
\hline \multirow{2}{*}{$\begin{array}{c}\text { Comtros } \\
\text { Comunales }\end{array}$} & \multirow{2}{*}{$\begin{array}{c}\text { Población } \\
\text { total }\end{array}$} & \multicolumn{7}{|c|}{$\begin{array}{c}\text { Argentinos } \\
\text { Aires }\end{array}$} & \% & $\begin{array}{c}\text { Otra } \\
\text { provincia }\end{array}$ & $\%$ & Total & $\%$ \\
\hline L. OLMOS & 17.872 & 12.653 & 70,8 & 889 & 24,2 & 4.330 & 5 \\
\hline M. ROMERO & 22.511 & 15.487 & 68,8 & 2.092 & 21,9 & 4.932 & 9,3 \\
\hline A. SEGUÍ & 6.115 & 4.162 & 68,1 & 474 & 24,2 & 1.479 & 7,8 \\
\hline GORINA & 5.521 & 3.754 & 68 & 267 & 27,2 & 1.500 & 4,8 \\
\hline ETCHEVERRY & 2.929 & 1.978 & 67,5 & 205 & 25,5 & 746 & 7 \\
\hline ABASTO & 6.799 & 4.574 & 67,3 & 666 & 22,9 & 1.559 & 9,8 \\
\hline EL PELIGRO & 1.862 & 1.065 & 57,2 & 325 & 25,3 & 472 & 17,5 \\
\hline HERNÁNDEZ & 6.320 & 4.710 & 74,5 & 487 & 17,8 & 1.123 & 7,7 \\
\hline SAN LORENZO & 30.192 & 23.851 & 79 & 1.244 & 16,9 & 5.097 & 4,1 \\
\hline LOS HORNOS & 54.406 & 42.533 & 78,2 & 3.027 & 16,3 & 8.846 & 5,6 \\
\hline VILLA ELVIRA & 59.476 & 46.385 & 78 & 3.531 & 16,1 & 9.560 & 5,9 \\
\hline SAN CARLOS & 43.266 & 33.583 & 77,6 & 2.577 & 16,4 & 7.106 & 6 \\
\hline RINGUELET & 13.473 & 11.056 & 82,1 & 742 & 12,4 & 1.675 & 5,5 \\
\hline CASCO & 186.524 & 150.434 & 80,7 & 9.007 & 14,5 & 27.083 & 4,8 \\
\hline M.GONNET & 22.963 & 18.843 & 82,1 & 876 & 14,1 & 3.244 & 3,8 \\
\hline TOLOSA & 41.705 & 33.755 & 80,9 & 2.745 & 12,5 & 5.205 & 6,6 \\
\hline CITY BELL & 32.646 & 25.204 & 77,2 & 1.501 & 18,2 & 5.941 & 4,6 \\
\hline VILLA ELISA & 19.643 & 14.767 & 75,2 & 1.009 & 19,7 & 3.867 & 5,1 \\
\hline TOTAL & 574.223 & 448.794 & 78,2 & 31.664 & 16,3 & 93.765 & 5,5 \\
\hline
\end{tabular}

Fuente: Elaboración propia en base a los datos proporcionados por la Dirección General de Estadística y Evaluación de Programas Especiales de la Municipalidad de La Plata. 
Los centros comunales en la tabla 2, están distribuidos según las tres zonas identificadas en relación a los índices de NBI. En este caso, encontramos los valores más altos en relación a la migración extranjera y de otras provincias en la zona de producción florihortícola, quedando evidenciado así lo que hemos denominado como cordón poblacional migrante visualizado en el siguiente gráfico. En él observamos dos grandes zonas. Los centros comunales desde Hernández que hacia la izquierda, corresponden a un área clara de recepción de población migrante; mientras hacia la derecha los valores más altos corresponden a población nacida en la Provincia de Buenos Aires, por lo tanto no indígena, no boliviana, no paraguaya.

Gráfico 2. Comparación entre los lugares de origen según sea Buenos Aires, otra provincia o extranjero, y el lugar de residencia.

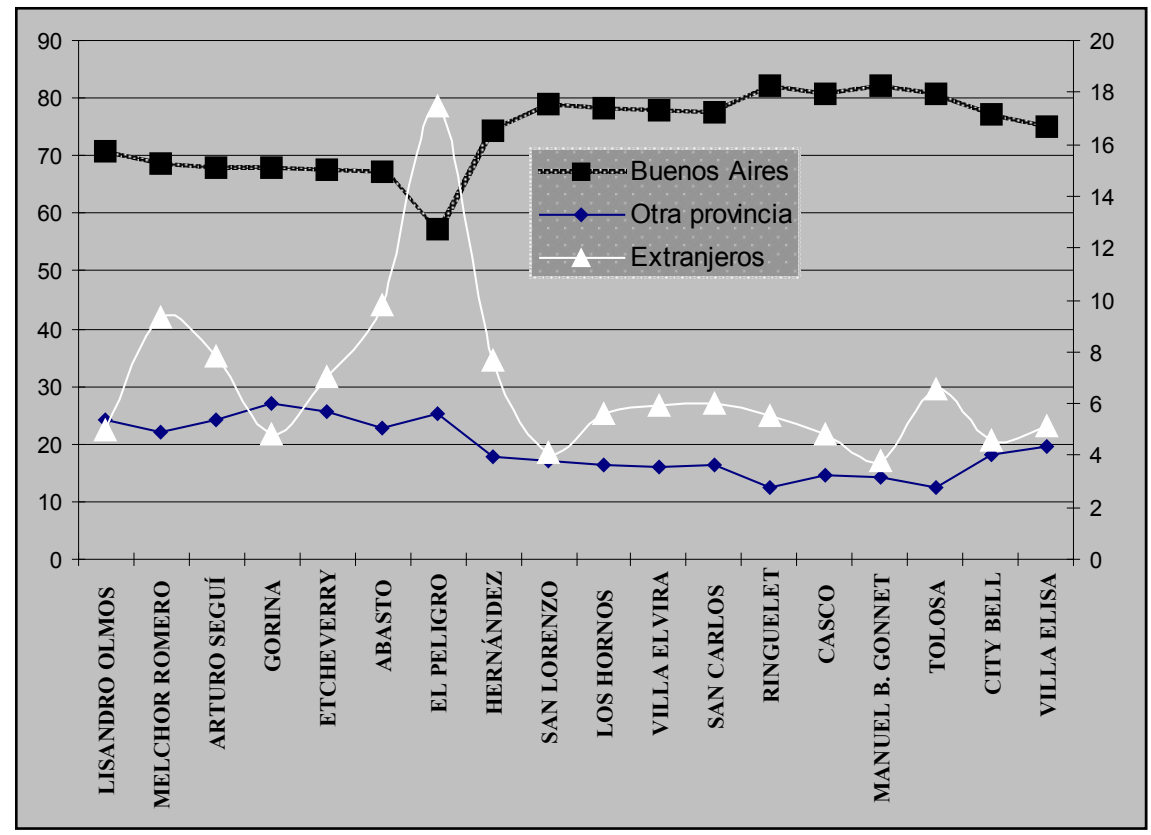

Fuente: Elaboración propia a partir de Tabla 2.

Los grupos domésticos de diferente procedencia geográfica y con características socio culturales singulares fueron conformando un cordón poblacional migrante, asentado en terrenos con suelos degradados, fiscales, inundables, y con escasos servicios, sin responder a pautas de urbaniza- 
ción, con la excepción de un predio planificado por el gobierno provincial para 540 viviendas. En este último, 36 grupos domésticos indígenas Qom lograron construir sus propias viviendas asesorados y subsidiados por entes del estado provincial (8). Esta experiencia motivó la posterior llegada del más del doble de familias indígenas que no logran ninguna contención gubernamental y soportan los mismos apremios de vivienda digna que el resto de los migrantes no indígenas.

En el plano laboral, los habitantes de este cordón poblacional tienen trabajos poco calificados con contrataciones precarias y modalidades a destajo (changarines, empleadas domésticas, peones, cartoneros, etcétera) sobrellevando las condiciones de desprotección que describen Bayon y Saraví (2002). En el mapa mostramos la ubicación de ese cordón poblacional asentado en los últimos veinte años y las escuelas a las que los niños de estas unidades domésticas asisten.

Algunas de estas escuelas, ya centenarias, presentan edificaciones que hoy resultan insuficientes para la demanda de escolarización. Se encuentran deterioradas infraestructuralmente, con sanitarios desbordados, servicio eléctrico y de calefacción dañados, con imperceptible contención por parte de la acción gubernamental. Respecto a la situación educativa han recurrido a efectuar un desplazamiento de los momentos y espacios de la enseñanza-aprendizaje por los momentos y espacios para la comida (desayunos, almuerzos y meriendas en algunas escuelas, y en otras los desayunos o meriendas reforzadas), respondiendo a las necesidades vitales de estos niños.

Resultan así condiciones paupérrimas que se equiparan a las que viven los niños y jóvenes en sus residencias, lo que va en detrimento de la educación que se propone impartir.

“... en estas escuelas lo que nosotros hacemos es no priorizar los contenidos. Nos adecuamos a la capacidad de los chicos que tenemos. Si aplicáramos los contenidos... la mitad de la escuela tiene que repetir de grado. Sabemos que no les podemos cambiar la vida. Esto es atender realmente a la diversidad. Cada chico es un mundo. Nosotros acá tenemos chicos desnutridos, golpeados, abandonados, la familia totalmente desintegrada...".

La situación educativa en la escuela implica la presencia del sujeto educador o educadora, el 'maestro' y la presencia de los educandos, de los 'alumnos' en un espacio que es el espacio pedagógico y en un tiempo pautado como tiempo educativo que está al servicio de la producción del saber. Sin embargo registramos situaciones educativas donde aparece el 
comedor o las meriendas reforzadas como el justificativo de la existencia de estas instituciones. Se repliega el espacio social pedagógico a 'adecuarse a la capacidad de los niños', a minimizar los contenidos; a prácticas cotidianas reproductoras de un 'como si' la escuela funcionara, exigiendo el uso del guardapolvo, la asistencia, y en la actividad áulica registramos lo que Edwards (1995) denomina 'conocimiento tópico' (9). Aquí nos preguntamos parafraseando a Freire (2003): al servicio de quiénes, de qué ideales, producen conocimiento los docentes conjuntamente con los alumnos dentro del tiempo-espacio de la escuela. ¿Cómo derribar los discursos y prácticas racistas sobre la desigualdad educativa que describen Llomovatte y Kaplan (2005)? (10).

\section{Máscaras en la interacción}

La escuela pública tiene el papel de interlocutora, nominando a los niños bajo un rol específico: alumno. Tipifica sus capacidades y conductas, "alumno regular", "alumno repetidor", "alumno desertor", "alumno violento", "genio", "inteligente". Califica sus acciones y saberes, si es "lento", "rápido", "incumplidor", "carenciado", "indisciplinado", "distraído", "no le da", "tímido". El alumno es adscripto a una sola pertenencia política (son apolíticos y subordinados), simbólica (hombres del futuro, hijos de la patria), lingüística (monolingües), social ("ser argentino"). Aquí las diferencias y las desigualdades sociales entran en relación, pero esa relación está pautada y establecida de antemano. El "adentro" escolar se torna un tanto "uniforme" (el guardapolvo y su exigencia de uso) y compulsivo (el maestro sabe y el alumno no); si se compara con el "exterior" diferente y diferenciado, el adentro escolar establece un tipo de relación con el conocimiento o pensamiento (que implica una descalificación de otros saberes no científicos), un tipo de sociabilidad, un conjunto de valoraciones éticas y estéticas, un tipo de relación de pertenencia (con una nación, la argentina; con un grupo, de clase; con una religión, la católica), un tipo de existencia legal y controlada (Documento Nacional de Identidad) sobre aquellos que forman parte de la institución, y una historia o memoria que explica, interpreta y legitima la realidad de las cosas: la historia ritualizada en el calendario escolar.

El antropólogo Eduardo Menéndez lo subrayó claramente en 1972 al dar cuenta de cómo el sistema capitalista de producción implica relaciones racistas que son legitimadas por el aparato científico de modo particular en cada momento histórico y se constituye como la manera normal de conexión y relación con otras formas socioculturales. “... el racismo debe ser referido a las formas de relaciones sociales y culturales que implican negación, discriminación, subordinación, compulsión y explotación de los 
otros en nombre de pretendidas posibilidades y disponibilidades ya sean biológicas, sociales o culturales..." (Menéndez, 1972).

La escuela como institución define, para constituirse como tal, la relación social docente-alumno, con una determinada forma-contenido, que queda cristalizada y opera compulsivamente como comportamiento esperado en la interacción. Foucault (1976) caracteriza esas relaciones como jerárquicas, en las que una de las partes se constituye siempre en modelo a seguir, y la otra en cuerpo perfectible, manipulable, controlable, por su incompletitud e incluso, su defecto o "anormalidad". El poder se coagula en uno de los términos de la relación y se recrea en las definiciones de las situaciones de interacción, en todo el contexto institucional pero sobre todo en el espacio del aula.

Más del ochenta por ciento de los testimonios de docentes recogidos lo ejemplifican, en el caso que presentamos se plantea el modo en que una docente de segundo grado de educación primaria, organiza la actividad en el aula:

"Armé tres grupos para trabajar y los senté juntos para poder avanzar. Tengo el grupo A que anda bien, responden rápidamente a las consignas, y constantemente les doy actividad para que estén ocupados, cumplen con los deberes para el hogar; el grupo B es más lento, tengo que dedicarles más tiempo, les doy menos ejercicios para que los terminen, pido ayuda a las mamás para que hagan los deberes; el grupo $\mathrm{C}$ son alumnos con problemas de aprendizaje, no comprenden las consignas, a ellos ya los derivé al gabinete psicopedagógico.

Tengo una nena toba (qom) que es más grande de edad, tiene pocas cosas en el cuaderno, mucho dibujo, reconoce algunas letras, viene a la escuela en micro. Le pregunto en qué micro venís y me contesta 'en el blanco', ¡ni siquiera sabe el número de la línea del micro que viaja todos los días! Eso ya te da la pauta de que 'no le da' (se refiere a su capacidad intelectual), le mando citaciones a los padres pero ninguno viene. Creo que es repetidora, ya le dije a la maestra recuperadora que es un caso para ella" (11).

En el mismo establecimiento escolar otro docente, en este caso de primer grado de la educación primaria, nos comenta que tiene, en su grupo, una niña toba (qom) que aun no le conoce la voz, que va muy limpita y peinada, que lleva su mochila con sus útiles pero que no le responde a sus consignas. Dice: "es inmadura, está sentada en su banco, se levanta y sale. Va a mirar en las otras aulas, pero no molesta”. Asegura que ya 
comunicó al gabinete porque van más de tres meses de clase y nunca la escuchó hablar (12).

Ya en la década de 1960 nos alertaba el antropólogo Cardoso de Oliveira respecto a la doble negación de ser indígena y la necesidad de "manipular" la identidad étnica para sobrellevar la existencia en un mundo definido y apoderado por los blancos, relata en uno de sus artículos:

"Escogióse entonces una escuela primaria de la población Duque Estrada, a ocho kilómetros de la aldea Cachoeirinha. Contamos con la colaboración de la profesora, que aceptó nuestra sugestión de pedir a los niños (entre siete y once años) pequeñas composiciones sobre el indio, sus hábitos y sus costumbres. El análisis de estos trabajos escolares demostró -lo que para nosotros fue sorprendente en la época (1957)- que la mayor parte de ellos hablaba de un indio abstracto, de "arco y flecha", adorando al sol y a la luna, es decir el indio presente en los libros de enseñanza; y los pocos alumnos que mencionaron a los terêna, lo hicieron llamándolos "bugres" (el equivalente del "caboclo" del Solimöes), "decadentes", "promiscuos", "alcohólicos", etc., siempre comparándolos con los "verdaderos indios", conocidos ciertamente en las lecciones de su profesora" (Cardoso de Oliveira, 1971).

En el transcurso de varios años de ser interlocutores con adultos indígenas son innumerables los hechos dolorosos unos y graciosos otros que nos han relatado respecto a circunstancias de interacción en las que se mostraban como indígenas y en las que ocultaron esa identidad. Sin embargo el caso de los niños y jóvenes resulta sumamente común el silencio frente a esa identificación. En una caminata que realizábamos con niños indígenas y no indígenas en el barrio, uno de ellos dijo "... no quiero hablar toba porque sino soy un indio" ante lo que todos sonrieron y uno le respondió "iiqué te hacés el inglés!!".

Muchas investigaciones dieron cuenta que al subestimar una lengua, se subestima con ello a quienes la hablan. Esto influye en las construcciones que los niños realizan durante el proceso de escolarización al tener sobrevalorada la lengua castellana, tanto en su oralidad como en la escritura, y minimizado el valor de las lenguas que escuchan habitualmente de boca de sus familiares (guaraní, qom, quechua) (Ibáñez Caselli et al., 2004; Ibáñez Caselli, 1999; Briones, 2004; Martínez Sarasola, 1996).

Lo mismo ocurre con la posibilidad de narrar oralmente una experiencia muy valorada por el niño y encontrar a alguien que la escuche. Ante un registro de observación de una clase en una escuela del sector noroeste, donde el eje temático era la construcción de árboles genealógicos y la pro- 
cedencia de los familiares, vivenciamos una situación que nos da cuenta de la importancia del abrir espacios a lo que el otro valora como importante para transmitir:

"En plena actividad, Antonio se traslada desde su lugar hacia la parte posterior del aula desde donde estoy realizando la observación. Me comenta en forma exhaustiva y detallada que sus familiares provienen de Jujuy, que su familia toda vez que dispone de los medios necesarios viaja a esa provincia todos los veranos, y que él lo espera ansioso. A continuación relata con todos los pormenores su conocimiento y sus vivencias respecto a los Carnavales, insiste en la belleza y alegría que significa participar en ellos. Enumera y menciona las características del carnaval, la descripción de los participantes, la escenografía, la vestimenta, los instrumentos, las funciones que los distintos grupos de edades tienen en la comparsa. Para que yo entienda, lo compara con los carnavales televisivos, y hace notar las diferencias que existen con respecto a los carnavales que se realizan en esas regiones del conurbano bonaerense; él nota que aquí se da una mayor participación de niños, por su mayor presencia en relación a la cantidad de adultos; la baja calidad de los materiales y la menor elaboración de las vestimentas. No escatimó esfuerzos en su relato y en los gráficos que efectuó para asegurarse que yo comprendiera el conocimiento que me transmitía".

Voltear el velo prejuicioso de frases censoras a la adscripción a una etnia, a un pueblo originario de América implicaría la construcción de subjetividades valoradas socialmente.

\section{Por una educación intercultural sin máscaras}

La tradición de estudios antropológicos platenses (Soprano, 2006) da cuenta del análisis de las máscaras en los grupos humanos, sean arqueológicos o etnográficos, pues afirman que "es uno de los elementos culturales más universalmente admitidos", se explica que están construidas con diversidad de materiales y que su funcionalidad social es indiscutida según la etnia de que se trate, el espacio y el tiempo histórico en el que se contextualice. En esta investigación educativa descubrimos máscaras que requieren ser investigadas para poder transformar las relaciones con "los otros" y construir una educación intercultural.

En la situación educativa nos aventuramos a parafrasear a Levi Strauss a fin de extender en la noción de alumno, el cuerpo enmascarado: 
El decorado [guardapolvo] está "hecho" para el rostro [niño], pero en otro sentido el rostro [niño] está predestinado a ser decorado, porque sólo por el decorado [guardapolvo] y mediante él, el rostro [niño] recibe su dignidad social [de ser alumno] y su significación mística. El decorado se concibe para el rostro, pero el rostro mismo no existe sino por el decorado. Ésta es, en definitiva, la dualidad del actor y su papel, y la noción de 'máscara' nos proporciona la clave". (Levi Strauss, 1977, p. 237).

La interculturalidad es una meta política que se ha aplicado en la educación indígena bilingüe e intercultural en toda América Latina como la política educativa indígena oficial, desplazando a las políticas asimilacionistas y dando importancia al aprendizaje de la lengua y la cultura propias. Sin embargo, los pueblos indígenas deben ser reconocidos, comprender que se han transformado, valorar sus saberes y sus formas de resolver lo cotidiano, superar los estereotipos y actuar positivamente frente a las tensiones y conflictos que genera la diversidad y desigualdad (Barabas, 2006; Tamagno, 2006).

Seguimos a Maimone y Edelstein (2004) cuando plantean para la situación escolar intercultural lograr intervincular, en igualdad de estatus, conocimientos provistos por marcos culturales diferentes. Todo intercambio cultural abre miles de preguntas, y conocer se trata de poder formularnos preguntas sobre el mundo y sobre nosotros mismos.

El lugar del docente es fundamental para romper las máscaras del ocultamiento y predisponerse a escuchar antes de prejuzgar.

Las reflexiones planteadas por Ibáñez Caselli et al. (2004) subrayan la "necesidad de que la escuela trabaje conjuntamente con la comunidad, e incluya a los otros niños no indígenas junto con sus saberes. De este modo se plantea una educación intercultural para todo migrante, víctimas de la negación, discriminación, estigmatización, violencia física y simbólica".

A modo de cierre transcribimos fragmentos de la intervención de don Rogelio Canciano (etnia Qom) en un acto a propósito de la conmemoración del "12 de Octubre" (2006) en una de las escuelas de la zona:

"Hemos llegado a la ciudad de La Plata por el "Plan Pro-Tierra". Estamos asentados en la calle 149 entre 35 y 36 (Barrio Malvinas). Después de tantas idas y vueltas queremos establecernos definitivamente aquí. Pensamos que la tenencia de las tierras es hoy una necesidad muy importante. Para la seguridad de nuestros hijos y para el desarrollo de nuestra comunidad (...).

El tiempo ha dejado profundas huellas en nuestra raza. Nuestros niños no entienden el idioma "Toba", una equivocación grande de 
nuestros padres y abuelos. Ellos deben saber nuestro idioma. Deben tener la oportunidad de aprender el castellano también, para su mejor desarrollo en esta sociedad que nos cobija. Los viejos se van muriendo y quedan nuestros hijos. Ellos tienen que saber hablar nuestro idioma, para que sean raza de nuestra raza. Si no es así el futuro los tomará sin historia, sin saber quiénes son (...).

Todavía el indígena no ha podido pronunciar su propia palabra para mostrar toda la profunda sabiduría que tiene su forma de ser y de ver el mundo. Tampoco ha podido contar su historia (...)".

De Colón en adelante, lo único que sabemos ha sido contado por el conquistador blanco. De esta manera los aborígenes nunca fueron escuchados. El silencio indígena no es porque lo haya querido, es que la voz de su pueblo FUE ATADA, como un árbol que se corta para que no dé frutos. Pero su raza permanece. Hoy está volviendo a renacer hacia un futuro con esperanza.

El árbol aborigen fue cortado de distintas maneras y en distintos momentos, pero no perdió sus raíces. Donde quedan raíces hay esperanza de vida. Los retoños, los brotes están pujantes.

Es hora de preguntarles a los no indígenas: ¿Qué posibilidades nos ofrecen? ¿Cuál es la deuda que tienen con el mundo aborigen? ¡Primogénito de estas tierras! ¿Qué posibilidad tenemos al acceso definitivo de estas tierras? ¿Qué posibilidad tenemos de educación digna?

\section{Notas Bibliográficas}

(1) Maguid (1995) analiza la evolución de la población migrante entre los censos de 1869 y 1991, y observa para Argentina que a partir de mediados del siglo XIX, además de la reducción que se da en la inmigración internacional en general, se produce un cambio en cuanto a su composición, que pasa a ser casi exclusivamente de países limítrofes.

Por otro lado y en particular, la mayor inmigración de países limítrofes, provienen de Paraguay, destacándose en el censo del año 2001 la llegada masiva de migrantes de Bolivia y Perú.

(2) Durante la última década del siglo XX el gobierno del Estado Argentino terminó de concretar una serie de medidas socio-económicas que venían perfilándose desde la Dictadura Militar, y que implicaron un aumento considerable de la desocupación y la pobreza: la privatización de empresas públicas (energéticas, de transporte, etc.), el aniquilamiento de la industria nacional, la desvalorización de la capacitación en oficios, la flexibilización de los contratos de trabajo, la apropiación de recursos naturales en manos de grupos internacionales, el 
desarrollo tecnológico que reemplaza mano de obra, la expansión de los monocultivos transgénicos (soja), entre otras.

(3) El artículo 75, inciso 17 en la Nueva Constitución de 1994 dice: "Corresponde al Congreso... Reconocer la preexistencia étnica y cultural de los pueblos indígenas argentinos: garantizar el respeto a su identidad y el derecho a una educación bilingüe e intercultural; reconocer la personería jurídica de sus comunidades, y la posesión y propiedad comunitarias de las tierras que tradicionalmente ocupan; y regular la entrega de otras aptas y suficientes para el desarrollo humano; ninguna de ellas será enajenable ni susceptible de gravámenes o embargos. Asegurar su participación en la gestión referida a sus recursos naturales y a los demás intereses que los afecten. Las provincias pueden ejercer concurrentemente estas atribuciones".

(4) El marco legal está contenido en la Ley de Educación Nacional $N^{\circ} 26.206$ (2006), en los artículos 52, 53 y 54 del Capítulo 11: Educación Intercultural Bilingüe.

Artículo 52.- La Educación Intercultural Bilingüe es la modalidad del sistema educativo de los niveles de Educación Inicial, Primaria y Secundaria que garantiza el derecho constitucional de los pueblos indígenas, conforme al art. 75 inc. 17 de la Constitución Nacional, a recibir una educación que contribuya a preservar y fortalecer sus pautas culturales, su lengua, su cosmovisión e identidad étnica; a desempeñarse activamente en un mundo multicultural y a mejorar su calidad de vida. Asimismo, la Educación Intercultural Bilingüe promueve un diálogo mutuamente enriquecedor de conocimientos y valores entre los pueblos indígenas y poblaciones étnica, lingüística y culturalmente diferentes, y propicia el reconocimiento y el respeto hacia tales diferencias.

Artículo 53.- Para favorecer el desarrollo de la Educación Intercultural Bilingüe, el Estado será responsable de: a) crear mecanismos de participación permanente de los/as representantes de los pueblos indígenas en los órganos responsables de definir y evaluar las estrategias de Educación Intercultural Bilingüe; b) garantizar la formación docente específica, inicial y continua, correspondiente a los distintos niveles del sistema; c) impulsar la investigación sobre la realidad sociocultural y lingüística de los pueblos indígenas, que permita el diseño de propuestas curriculares, materiales educativos pertinentes e instrumentos de gestión pedagógica; d) promover la generación de instancias institucionales de participación de los pueblos indígenas en la planificación y gestión de los procesos de enseñanza y aprendizaje; e) propiciar la construcción de modelos y prácticas educativas propias de los pueblos indígenas que incluyan sus valores, conocimientos, lengua y otros rasgos sociales y culturales.

Artículo 54.- El Ministerio de Educación, Ciencia y Tecnología, en acuerdo con el Consejo Federal de Educación, definirá contenidos curriculares comunes que promuevan el respeto por la multiculturalidad y el conocimiento de las culturas originarias en todas las escuelas del país, permitiendo a los/as alumnos/as valorar y comprender la diversidad cultural como atributo positivo de nuestra sociedad. 
(5) Testimonio del Director de una de las escuelas del cordón poblacional migrante. Cuando menciona Plan Trabajar-Plan Jefe y Jefas de Hogar se refiere a planes de gobierno que otorgan subsidios mensuales a quienes están desocupados para que puedan sobrellevar la desocupación laboral de la década de 1990.

(6) Para este autor la articulación social implica observar y describir las características peculiares de las unidades en cuanto a su estructuración e institucionalización; enumerar los tipos diferentes de recursos involucrados en la actividad; observar los roles o papeles sociales que vehiculizan la conexión, particularizar las orientaciones generales que cada una de las unidades generan para definir las estrategias de los actores individuales y colectivos y finalmente, averiguar la dimensión histórica de cada una que afecta las modificaciones y tendencias de la articulación.

(7) Específicamente, un hogar con NBI es aquél que presenta al menos uno de los siguientes indicadores de privación: Hacinamiento (más de tres personas por cuarto), Vivienda (habitan en una vivienda de tipo inconveniente (pieza de inquilinato, pieza de hotel o pensión, casilla, local no construido para habitación o vivienda móvil), excluyendo casa, departamento y rancho), Condiciones Sanitarias (no tienen ningún tipo de retrete), Asistencia Escolar (tienen al menos un niño en edad escolar ( 6 a 12 años) que no asiste a la escuela) y Capacidad de subsistencia (tienen cuatro o más personas por miembro ocupado, cuyo jefe no ha completado el tercer grado de escolaridad primaria). "La pobreza en la Argentina (serie Estudios INDEC, N 1, Buenos Aires, 1984).

(8) Indígenas Qom conformaron la Asociación Civil Ntaunaq Nam Qom (Trabajando Juntos) con personería jurídica para gestionar ante el gobierno provincial la autoconstrucción de 36 viviendas en el marco del Plan Pro-tierra (Tamagno, 2001).

(9) Edwards denomina conocimiento tópico cuando se enfatiza el nombrar correctamente los términos aislados antes que utilizar el conocimiento. El conocimiento tópico produce una configuración del contenido cuyos elementos son datos que tiene sólo una relación de contigüidad y que se presentan mediante términos más que mediante conceptos (p. 150).

(10) Las autoras Llomovatte y Kaplan presentan en este texto una serie de ponencias y reflexiones producto de una jornada académica: Determinismo biológico, innatismo y exclusión en las tesis neoliberales sobre las desigualdades educativas. Hacia la construcción de discursos y practicas alternativos en la producción de subjetividades, realizado en diciembre de 2002 en la Facultad de Filosofía y Letras de la Universidad Nacional de Buenos Aires.

(11) Se trata de Adela, una niña de 9 años que vive en el barrio toba de viviendas autoconstruidas, su grupo doméstico está constituido por sus padres, cuatro hermanos/as mayores. Su padre trabaja en una obra en el gran Buenos Aires a tres horas de viaje en transporte automotor, por lo que muchas veces regresa los fines de semana. Su madre y hermanas colaboran en todas las tareas que ha emprendido la Asociación Civil Ntaunaq Nam Qom de la que son miembros (huerta comunitaria-confección y arreglo de ropa donada, comedor comunitario, 
artesanías para la venta, etc.). Se muestra vergonzosa en la relación cara a cara, le gusta dibujar y cuenta que ella hace lo que le dice la maestra, que le cuesta leer pero que está aprendiendo. Que en los recreos juega al elástico, a saltar con las amigas del recreo.

(12) Se trata de Daniela, una niña de 6 años con dos hermanos más pequeños que habita una de las viviendas auto construidas junto a su madre y sus abuelos también en el barrio de la Asociación Civil Qom. Cabe señalar que ante una tarea que, como equipo de investigación, realizamos en la escuela, respondió activamente. La consigna fue que el niño que conociera algo de lo que aparecía en una serie de fotos sobre el barrio y sus actividades las describiera para todos. Fue justamente Daniela quien habló extensamente para contar al resto del grupo quiénes estaban en las imágenes y qué estaban haciendo.

\section{Referencias Bibliográficas}

- Barabas. A. (2006) "Notas sobre multiculturalismo e Interculturalidad", en Diversidad y Reconocimiento. Suplemento de Diario de Campo 39, pp. 1319.

- Bartolomé, L. (1972) “El concepto de articulación social”, en Revista del Instituto de Desarrollo Económico y Social. Vol. 67, pp. 149-158.

- Bayon, C. y Yaraví, G. (2002) "Vulnerabilidad social en la Argentina de los años noventa: impacto de la crisis en el Gran Buenos Aires". En: Kaztman, R. y Wormald, G. (Coord.).Trabajo y Ciudadanía. Los cambiantes rostros de la integración y exclusión social en cuatro áreas metropolitanas de América Latina. Uruguay, Cebra, pp.61-131.

- Berger, P. y Luckmann, T. (1978) La construcción social de la realidad. Buenos Aires, Amorrortu.

- Briones, C. (2004) "Pueblos Indígenas y Antropología en Argentina (19942004)", en Anuario de Estudios en Antropología Social. Buenos Aires: Centro de Antropología Social - Instituto de Desarrollo Económico y Social, pp. 83100.

- Cardoso De Oliveira, R. (1971) Identidad étnica, identificación y manipulación. América Indígena, Vol. XXXI. № 4, pp. 923-953.

- Censo Nacional de Población, Hogares y Vivienda (2001) Dirección Provincial de Estadística. Instituto Nacional de Estadística y Censos.

- Centro comunales del Partido de La Plata. Hogares con NBI (2001) Dirección General de Estadística y Evaluación de Programas Especiales de la Municipalidad de La Plata www.estadistica.laplata.gov.ar, visitada el 31/08/2006.

- Censo Provincial Hortiflorícola. Región La Plata. (2005) Dirección General de Estadística y Evaluación de Programas Especiales de la Municipalidad de La Plata www.estadistica.laplata.gov.ar, visitada el 31/08/2005. 
- Dussell, I. (2000) "Historia de guardapolvos y uniformes: sobre cuerpos, normas e identidades en la escuela", en Gvirtz, S. (Comp.) Textos para pensar el día a día escolar. Buenos Aires, Santillana, pp.105-132.

- Edwards, V. (1995) Las formas de conocimiento en el aula, en Rocwell, E. (Coord.). La escuela cotidiana. México, Fondo de Cultura Económica, pp. 145-172.

- $\quad$ Foucault, M. (1976) Vigilar y Castigar. Madrid, Siglo XXI.

- Freire, P (2003) El grito manso. Buenos Aires, Siglo XXI.

- García, S. y Paladino, M. (2007) Educación Escolar Indígena. Investigaciones Antropológicas en Brasil y Argentina. Buenos Aires, Antropofagia.

- Hurtado, M. (2006) Análisis ambiental del partido de La Plata: Aportes al ordenamiento territorial. La Plata, Consejo Federal de Inversiones, $1^{\text {a }}$ ed.

- Ibáñez Caselli, A. (1999) Políticas lingüísticas y territorio. Una reflexión a través de los casos de indígenas toba migrantes, en Boletím Do Museu Paraense Emilio Goeldi, Serie Antropología 15 (2). Brasil, pp. 251-270.

- Ibáñez Caselli, A., Alaniz, A., Gomez, J., Fernández, T., Fernández, E., Rojas, A., Alegre, T. y Medina, L. (2004) "Reflexiones para una propuesta educativa para las comunidades Toba migrantes en la provincia de Buenos Aires-Argentina". En Solís Fonseca, G. (Ed.) Cuestiones de lingüística general, hispánica y aplicada. Tercer Congreso Nacional de Investigaciones Lingüísticofilológicas. Lima, Fondo Editorial de UNMSM, $1^{\text {a }}$ ed.

- Levi Strauss, C. (1977) Antropología Estructural. Buenos Aires, Eudeba, $7^{a}$ ed.

- Llomovatte, S. y Kaplan, C. (Coord.) (2005) Desigualdad educativa. La naturaleza como pretexto. Buenos Aires, Noveduc.

- Maguid, A. (1995) Migrantes limítrofes en la Argentina: su inserción e impacto en el mercado de trabajo. En Revista de Estudios del Trabajo. №10.

- Maimone, M. C. y Edelstein, P. (2004) Didáctica e Identidades culturales. Acerca de la dignidad en el proceso educativo. Buenos Aires, Editorial Stella - Ediciones La Crujía.

- Menéndez, E. (1972) Racismo, colonialismo y violencia científica, en Revista Transformaciones. Centro editor de América Latina.

- Montesinos, M. P. y Pallma, A. (2001) "Contextos urbanos e instituciones escolares. Los "usos" del espacio y la construcción de la diferencia", en Neufeld, M. R. y Thisted, D. "De eso no se habla..." Los usos de la diversidad sociocultural en la escuela. Buenos Aires, Eudeba.

- $\quad$ Pineau, P. (2005) "Del otro lado del muro: representaciones del afuera escolar en la matriz pedagógica argentina”, en Historia de la Educación. Anuario $\mathrm{N}^{\circ} 6$. Buenos Aires, Prometeo libros, pp. 119-128.

- Rockwell, E. (Coord.) (1995) La Escuela Cotidiana. México, Fondo de Cultura Económica. 
- Martínez Sarasola, C. (1992) Nuestros paisanos los indios. Vida, historia y destino de las comunidades indígenas en la Argentina. Buenos Aires, Emecé.

- Segato, R. (2002) Identidades políticas y alteridades históricas. Una crítica a las certezas del pluralismo global. Nueva Sociedad 178, pp. 104-125.

- Soprano, G. (2006) Continuidad y cambio en los estudios en etnología de poblaciones indígenas contemporáneas y comunidades folk en la Facultad de Ciencias Naturales y Museo de la Universidad Nacional de La Plata (19301976), en Anuario de Estudios en Antropología Social. Buenos Aires, Centro de Antropología Social del Instituto de Desarrollo Económico y Social, pp. 23-51.

- Szulc, A. y Hercht, C. (2004) Los niños indígenas, sus subjetividades y la escuela. Ponencia II Congreso Nacional de Sociología. Facultad de Ciencias Sociales. Universidad de Buenos Aires.

- Tamagno, L. (2001) Nam Qom Hueta'a Na Doqshi Lma. Los tobas en la casa del hombre blanco. Identidad, memoria y utopía. Buenos Aires, Al Margen.

- Tamagno, L. (2006) Interculturalidad. Una revisión desde y con los pueblos indígenas, en Diversidad y Reconocimiento. Suplemento de Diario de Campo 39, pp. 21-31.

- Tedesco, J.C. (2000) Educar en la sociedad del conocimiento. Buenos Aires, F.C.E. 